\title{
Capacidade Antioxidante do Extrato do pó da amêndoa do caroço da manga por diferentes técnicas de extração
}

\author{
Antioxidant capacity of mango kernel powder extract by different extraction Techniques \\ Capacidad antioxidante del extracto de polvo de hueso de mango mediante diferentes técnicas de \\ extracción
}

Recebido: 30/06/2021 | Revisado: 09/07/2021 | Aceito: 12/07/2021 | Publicado: 22/07/2021

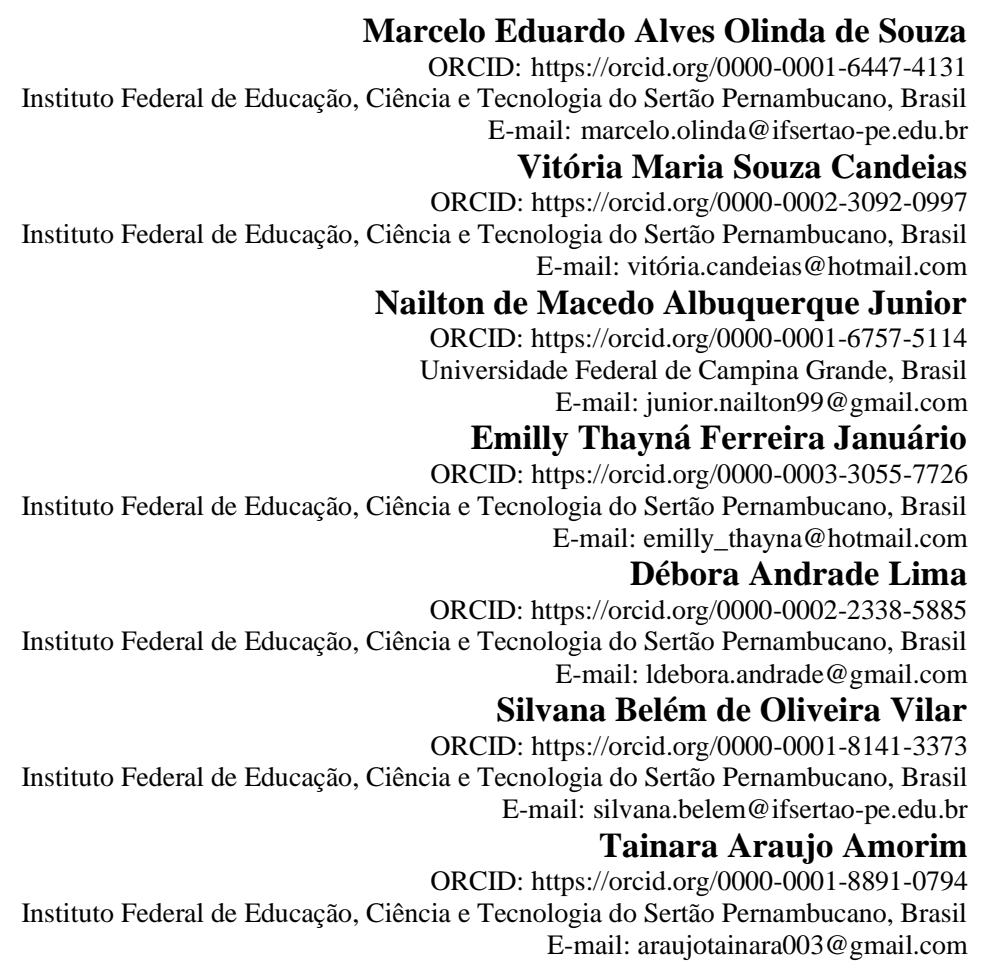

\begin{abstract}
Resumo
A manga é uma fruta amplamente cultivada no mundo, cujo processamento industrial gera resíduos, onde estes são ricos em compostos fenólicos. Com isso, o presente trabalho objetivou estudar o aproveitamento da amêndoa do caroço da manga para a obtenção de extratos com atividade antioxidante aplicando técnicas de extração como o sistema Soxhlet, maceração e assistida por ultrassom, utilizando diferentes solventes. Para obtenção da farinha, as amêndoas passaram pelo processo de secagem por circulação ar forçado a $60^{\circ} \mathrm{C}$. Os extratos obtidos foram avaliados pelo rendimento do processo de extração, teor de fenólicos totais (TFT) utilizando o método de Folin-Ciocalteu e atividade antioxidante (AA) pelos métodos de radicais livres ABTS e DPPH. Tratando-se de rendimento de extrato, o método de extração por Soxhlet com etanol apresentou o melhor desempenho quando comparado aos demais $(18,78 \%)$, devido ao etanol ser mais polar que o hexano e acetato de etila. Quanto ao TFT, o método de maceração utilizando etanol apresentou 451,32 $\mathrm{mg}$ EAG/g como melhor resultado, visto que é um método que não utiliza aquecimento. Para atividade antioxidante por ABTS e DPPH, os valores obtidos foram 2727,23 mM TEAC/g e 3198,58 mM TEAC/g, respectivamente, para extratos obtidos através da técnica de maceração com o etanol, tendo a melhor execução na captura dos radicais livres. Dessa forma, o resíduo agroindustrial da manga é um coproduto interessante para ser reaproveitado, visando reduzir o descarte inadequado, e substituir os antioxidantes sintéticos na indústria, como também em elaboração de alimentos funcionais. Palavras-chave: Fruta; Métodos; Compostos; ABTS e DPPH; Resíduo.
\end{abstract}

\section{Abstract}

The mango is a widely cultivated fruit in the world, whose industrial processing generates waste, which are rich in phenolic compounds. Thus, the present work aimed to study the use of mango kernel to obtain extracts with antioxidant activity by applying extraction techniques such as soxhlet system, maceration and ultrasound-assisted, using different solvents. To obtain the flour, the almonds were dried by forced air circulation at $60{ }^{\circ} \mathrm{C}$. The extracts obtained were 
evaluated by the yield of the extraction process, total phenolic content (TFT) using the Folin-Ciocalteu method and antioxidant activity (AA) by the ABTS and DPPH free radical methods. Regarding the extract yield, the extraction method by Soxhlet with ethanol showed the best performance when compared to the others (18.78\%), because ethanol is more polar than hexane and ethyl acetate. As for the TFT, the maceration method using ethanol showed $451.32 \mathrm{mg}$ EAG/g as the best result, since it is a method that does not use heating. For antioxidant activity by ABTS and DPPH, the values obtained were $2727.23 \mathrm{mM} \mathrm{TEAC/g}$ and $3198.58 \mathrm{mM}$ TEAC/g, respectively, for extracts obtained through the maceration technique with ethanol, having the best performance in capturing free radicals. Thus, the mango agroindustrial residue is an interesting co-product to be reused, in order to reduce the inadequate disposal, and replace synthetic antioxidants in the industry, as well as in the preparation of functional foods.

Keywords: Fruit; Methods; Compounds; ABTS and DPPH; Residue.

\section{Resumen}

El mango es una fruta ampliamente cultivada en el mundo, cuyo procesamiento industrial genera residuos, donde éstos son ricos en compuestos fenólicos. Así, el presente trabajo tuvo como objetivo estudiar el aprovechamiento de la almendra de mango para la obtención de extractos con actividad antioxidante mediante la aplicación de técnicas de extracción como el sistema soxhlet, la maceración y la asistida por ultrasonidos, utilizando diferentes disolventes. Para obtener la harina, las almendras se sometieron al proceso de secado por circulación forzada de aire a $60^{\circ} \mathrm{C}$. Los extractos obtenidos fueron evaluados por el rendimiento del proceso de extracción, el contenido fenólico total (TFT) mediante el método de Folin-Ciocalteu y la actividad antioxidante (AA) por los métodos de los radicales libres ABTS y DPPH. En cuanto al rendimiento del extracto, el método de extracción por Soxhlet con etanol mostró el mejor rendimiento en comparación con los demás (18,78\%), debido a que el etanol es más polar que el hexano y el acetato de etilo. En cuanto al TFT, el método de maceración con etanol mostró 451,32 mg EAG/g como el mejor resultado, ya que es un método que no utiliza el calentamiento. Para la actividad antioxidante por ABTS y DPPH, los valores obtenidos fueron de $2727,23 \mathrm{mM}$ TEAC/g y $3198,58 \mathrm{mM}$ TEAC/g, respectivamente, para los extractos obtenidos mediante la técnica de maceración con etanol, teniendo el mejor desempeño en la captura de radicales libres. Por lo tanto, el residuo agroindustrial del mango es un coproducto interesante para ser reutilizado con el fin de reducir la eliminación inadecuada y sustituir los antioxidantes sintéticos en la industria, así como en la preparación de alimentos funcionales.

Palabras clave: Fruta; Métodos; Compuestos; ABTS y DPPH; Residuo.

\section{Introdução}

O contínuo crescimento da fruticultura mundial e a diversidade de variedades de frutas cultivadas possibilitam sua utilização pela indústria alimentícia. O Brasil ocupa o terceiro lugar na produção mundial de frutas, respondendo por 4,6\% da produção total, com uma produção de 39,9 milhões de toneladas (Seab/Deral, 2020).

Embora a água e o solo sejam restritos na região semiárida, o Nordeste do Brasil destaca-se como um grande produtor e exportador, tendo importante significado econômico e social em diversas áreas. No Vale do Submédio São Francisco, a produção de manga para o mercado externo é notável, comparando com o mesmo período de 2019, o primeiro semestre de 2020 aumentou cerca de 5\% (Abrafrutas, 2020).

A manga (Mangifera indica L.) se destaca entre as frutas tropicais por sua significativa contribuição para as exportações de frutas frescas do Brasil (Agrianual, 2019), e tem conquistado a preferência dos consumidores por seu sabor e aroma atrativos, com grande expressividade no comércio agrícola internacional. No Brasil, as regiões Nordeste e Sudeste são as principais produtoras de manga, tendo um conjunto de 99,2\% do volume nacional. Entre 2017 e 2018, Pernambuco foi o maior produtor entre os principais estados produtores, aumentando $105,4 \%$, passando do $2^{\circ}$ lugar para o $1^{\circ}$ no ranking nacional, ultrapassando a Bahia (IBGE, 2018).

$\mathrm{O}$ aumento das atividades agroindustriais tem afetado a geração de grandes quantidades de resíduos na agricultura, indústria e áreas urbanas (FAO, 2013; Pedrassolli et al., 2015; Silva, 2015). A indústria de alimentos, principalmente as processadoras de suco de frutas, acabam descartando uma grande quantidade de substratos que haviam sido negligenciados no meio ambiente, como bagaço, cascas e sementes (Nascimento Filho e Franco, 2015). A diminuição da quantidade de resíduos descartados na natureza, assim como o aproveitamento integral dos alimentos é uma alternativa para solucionar o impacto ambiental acometido por esses resíduos gerados pela indústria de alimentos, pois possibilita a utilização de todas as partes que seriam descartados, mas que possuem valor nutricional significativo (Silva et al., 2017). 
A produção de farinha através do processo de secagem torna-se a alternativa ao uso de resíduos industriais, pois é um componente importante, rico em fibras, compostos bioativos, minerais, vitaminas e antioxidantes e tem vários impactos positivos à saúde (Marques, 2013; Brizola, 2014). O desenvolvimento de farinha permite a produção de novos produtos que podem aumentar as propriedades sensoriais, especialmente sabor e aumentar os nutrientes que são cada vez mais necessários no mercado para seus numerosos benefícios para a saúde (Macagnan et al., 2014).

Com a elaboração de farinhas, pode ser aplicada em vários subprodutos, como por exemplo extratos que possuem atividade bioativa presentes no material. Dessa forma, para se obter esses extratos várias metodologias clássicas, denominadas também de metodologias convencionais para a extração de compostos bioativos, entretanto esses métodos de extração oferecem desvantagens como elevado consumo de energia, baixa eficiência e longo tempo de extração (Naffati et al., 2017). Com isso, os extratos cuja composição possui compostos fenólicos antioxidantes, são de particular interesse para a indústria alimentícia, tendo com funcionalidade a conservação de alimentos, podendo ser usado como ingrediente funcional e/ou aditivo natural.

Sendo assim, devido ao aumento da preocupação em relação às questões ambientais quanto ao resíduo agroindustrial de frutas, assim como a elevada importância dos funcionais para a área de Ciência e Tecnologia de Alimentos, o presente estudo visa avaliar as extrações dos compostos bioativos e atividade antioxidante a partir do resíduo agroindustrial da manga (Mangifera indica $L$.), através de diferentes métodos de extração e solventes, para obter um produto de maior valor agregado.

\section{Metodologia}

O presente trabalho foi realizado no Instituto Federal de Educação, Ciência e Tecnologia do Sertão Pernambucano, Campus Petrolina-PE, no Laboratório Experimental de Alimentos (LEA) e Laboratório de Águas e Bebidas. A abordagem metodológica foi determinada de forma quantitativa, recolhendo dados por meio das medições de grandezas, produzindo dados que podem ser avaliados através de métodos matemáticos como porcentagens, estatísticas e probabilidades, além de métodos numéricos, analíticos e o desenvolvimento de equações e/ou fórmulas matemáticas aplicáveis a algum processo (Pereira et al., 2018).

\subsection{Preparo da Matéria-prima}

Os resíduos (caroços) de manga da espécie Tommy Atkins foram fornecidos por um servidor do IF Sertão - PE /Campus Petrolina, em seguida sendo levados até o Laboratório Experimental de Alimentos (LEA), localizado no instituto. Foi realizada uma seleção dos caroços que não apresentavam danos físicos, onde estes, posteriormente, foram submetidos ao processo de remoção do excesso de polpa aderida neles, com auxílio de facas de aço inox, seguido de uma higienização em água corrente.

\subsection{Secagem}

Os caroços foram submetidos à secagem em secador por circulação de ar forçado (Desidratador Pardal PE 30, 220 V, $900 \mathrm{~W}$ ) na temperatura de $60^{\circ} \mathrm{C}$, sendo estes pesados a cada 1 hora até obtenção de peso constante.

Totalmente secos, os caroços foram abertos manualmente com facas para retirada de suas amêndoas, quais também passaram pelo mesmo processo de secagem que os caroços foram submetidos até peso constante.

As amêndoas secas foram trituradas em liquidificador industrial (JL COLOMBO, 8 Litros) por 5 minutos em velocidade máxima, assim obtendo a farinha da amêndoa do caroço da manga (FACM), que em seguida foi peneirada em peneira granulométrica de aço inox (bronzinox) de 10 mesh.

A farinha foi pesada, dividida em diversas porções e embalada em papel alumínio e posta em saquinhos plásticos de Polietileno de Baixa Densidade (PEBD). 


\subsection{Regentes}

Os solventes utilizados nas extrações de baixa pressão foram: o etanol P.A. (EtOH), que é um solvente não tóxico obtido de fontes renováveis e que é bastante utilizado em indústrias alimentícias; o hexano P.A. (Hx) que é o solvente orgânico mais utilizado no processo de extração de óleos, por ser mais seletivo, possuir estreita faixa de ebulição e ser imiscível com a água; e o acetato de etila P.A. (EtAc), que de acordo com Tiwari (2015), é considerado um solvente GRAS (geralmente reconhecido como seguro) e possui propriedades semelhantes aos do hexano, o que permite sua substituição.

Na Tabela 1, são apresentados os dados relacionados ao ponto de ebulição e polaridade destes solventes.

Tabela 1. Ponto de ebulição e polaridade dos solventes.

\begin{tabular}{ccc}
\hline Solventes & Ponto de Ebulição $^{\mathbf{1}}$ & Polaridade $^{\mathbf{2}}$ \\
\hline Etanol & $78,3^{\circ} \mathrm{C}$ & 5,2 \\
\hline Hexano & $69^{\circ} \mathrm{C}$ & 0 \\
\hline Acetato de Etila & $77^{\circ} \mathrm{C}$ & 4,4 \\
\hline
\end{tabular}

${ }^{1}$ Fonte: Di Vitta, (2013). ${ }^{2}$ Fonte: Souza, (2015).

\subsection{Extração a baixa pressão}

\subsubsection{Método Soxhlet}

As extrações para obtenção de extrato por sistema Soxhlet foram executadas de acordo com a metodologia do Instituto Adolfo Lutz (IAL - $4^{\mathrm{a}}$ edição, 2008). Foram pesadas 5 gramas da matéria-prima, posteriormente postas em cartuchos de filtro de café e encaixados ao extrator de óleo e graxas (MARCONI, MA 491). No copo de extrator, foram depositados $150 \mathrm{~mL}$ de solvente, em seguida, acoplado no sistema, tendo o aquecimento ligado de acordo com o ponto de ebulição do solvente, tendo duração de 6 horas de extração.

\subsubsection{Método Maceração}

O método de maceração consiste em uma extração da matéria-prima a temperatura ambiente em recipiente fechado, com duração de 5 dias, sob agitação manual de 1 vez ao dia, utilizando solvente orgânico (Sachindra et al., 2006). Seguindo este método, em um frasco tipo âmbar, foram adicionadas 25 gramas da amostra e $100 \mathrm{~mL}$ de solvente para efetuar a extração. Passado o período estabelecido, foi realizada uma filtração a vácuo para remoção da amostra sólida do extrato.

\subsubsection{Método Ultrassom}

Foi utilizado o método adaptado de Gu et al. (2008) que consiste na extração da matéria-prima, a temperatura ambiente, adicionado $5 \mathrm{~g}$ de matéria-prima com $150 \mathrm{~mL}$ de solvente orgânico. Para isso, em balão volumétrico foi depositado a amostra e o solvente, onde este recipiente foi tampado e mergulhado em uma lavadora ultrassônica (USC-700/55 kHz, Unique Ind. e Com. de produtos Eletrônicos Ltda., Indaiatuba/SP, Brasil), durante o período de 60 min de extração. Ao final, foi feita uma filtração a vácuo para separação da amostra do extrato.

\subsubsection{Eliminação do solvente por rotaevaporação}

Ao final de cada extração, os extratos foram submetidos ao processo de remoção do solvente presente neles, em rotaevaporador (Fisatom 801 - Mod. 550 / 200 RPM; 230 V; 60 Hz; 1200 W, Brasil) com rotação de 60 rpm, em condições a 
vácuo e com temperatura próxima ou igual ao ponto de ebulição do solvente empregado. A amostra foi depositada em um balão de fundo chato sob rotação imerso no banho de água aquecida.

A rotação do frasco cria uma superfície de troca, devido ocorrer uma maior mistura, assim permitindo realizar a evaporação de maneira rápida (Souza, 2015). Após eliminação total do solvente, o extrato na sua forma pastosa foi pesado juntamente do frasco âmbar, qual havia sido pesado vazio com antecedência para realização do cálculo de rendimento. O acondicionamento destes recipientes contendo as amostras foi feito em freezer a $-18^{\circ} \mathrm{C}$.

\subsection{Determinação do rendimento global das extrações $\left(X_{0}\right)$}

Silva (2004) define rendimento global de extrações como a quantidade total de composto oleico extraído de um elemento, sendo obtido através de solventes, em conjunto com as condições pré-estabelecidas. Dentre estas, pode-se citar o tempo de extração e a quantidade de matéria-prima utilizada.

Foi calculado o rendimento das extrações $\left(\mathrm{X}_{\mathrm{o}}\right)$ por meio de uma equação que expressa à razão entre a massa de extrato $\left(\mathrm{m}_{\mathrm{ext}}\right)$ obtido e a massa da farinha da amêndoa do caroço da manga $\left(\mathrm{m}_{\mathrm{far}}\right)$, demonstrada na equação 1 .

Equação 1. Equação para cálculo de rendimento das extrações.

$$
\text { Xo }(\%)=\frac{m_{\text {ext }}}{m_{\text {far }}} \times 100
$$

Onde:

$\mathrm{X}_{0}=$ rendimento global $(\%)$

$\mathrm{m}_{\mathrm{ext}}=$ massa do extrato

$\mathrm{m}_{\mathrm{far}}=$ massa da farinha da amêndoa do caroço da manga.

\subsection{Caracterização dos compostos bioativos}

\subsubsection{Determinação do teor de fenólicos totais (TFT)}

O Teor de Fenólicos Totais (TFT) contido nos extratos da amêndoa do caroço da manga foi determinado através do método espectrofotométrico com o reagente Folin-Ciocalteu, seguindo a metodologia descrita por Singleton e Rossi (1965) adaptada por Lima et al. (2014). Inicialmente foram pesadas $10 \mathrm{mg}$ do extrato da amêndoa do caroço da manga e em seguida foi feita a diluição do mesmo em $1 \mathrm{~mL}$ de etanol. Em tubos de ensaio foram adicionados $50 \mu \mathrm{L}(0,05 \mathrm{~mL})$ das amostras antecipadamente diluídas, $3,95 \mathrm{~mL}$ de água destilada e $250 \mu \mathrm{L}(0,25 \mathrm{~mL})$ do reagente Folin-Ciocalteu. Foram contabilizados de 3 a 8 minutos para fazer a adição de $750 \mu \mathrm{L}(0,75 \mathrm{~mL})$ da solução saturada de carbonato de sódio $\left(\mathrm{Na}_{2} \mathrm{CO}_{2}\right)$ a $20 \%$, depois foi feita a homogeneização e as amostras foram guardadas em repouso por 2 horas. Ao término desse período de repouso, a leitura da absorbância foi feita a $765 \mathrm{~nm}$ em cubetas de vidro de $10 \mathrm{~mm}$ de percurso óptico em espectrofotômetro UV-Visível (UV 2000A, Instrutherm, Brasil) zerado com água destilada. Os resultados de absorbâncias obtidas foram comparados com a curva de calibração do ácido gálico e expressos em mg EAG/g de Fenólicos Totais equivalentes ao ácido gálico.

\subsubsection{Determinação da atividade antioxidante por ABTS}

A atividade antioxidante do extrato da amêndoa do caroço da manga foi estabelecida através do método de captura do radical livre 2,2'-azino-bis (ácido 3-etilbenzotiazolino-6-sulfónico) (ABTS) seguindo a metodologia de Re et al. (1999) adaptada por Lima et al. (2014), o qual é fundamentado na captura do radical ABTS por antioxidantes, onde gera uma redução da 
absorbância em $734 \mathrm{~nm}$, podendo esta redução ser colacionada a obtida por um antioxidante conhecido como TROLOX (6hidroxi-2,5,7,8-tetrametilcromato-2-ácido carboxílico).

Antes de realizar a análise, foi feito o preparo do radical ABTS, onde foi utilizado $1932 \mu \mathrm{L}$ da solução estoque de ABTS e $64 \mu \mathrm{L}$ da solução de persulfato de potássio. A solução ficou guardada no escuro, em temperatura ambiente, por volta de 16 a 24 horas para ser utilizada. Após este período, $1 \mathrm{~mL}$ desta mistura foi sendo diluída em álcool etílico até a obtenção da absorbância desejada, que é de $0,650 \pm 0,750 \mathrm{~nm}$ a $734 \mathrm{~nm}$.

Para determinação da atividade antioxidante, em tubos de ensaio foram adicionados $30 \mu \mathrm{L}$ do extrato diluído e $3,0 \mathrm{~mL}$ da solução ABTS previamente diluída em etanol. Para preparo do controle, em outro tubo foi colocado $30 \mu \mathrm{L}$ de água destilada e 3,0 mL da solução ABTS. Todos os tubos foram agitados e, com o espectrofotômetro zerado com etanol, tiveram as absorbâncias lidas em $734 \mathrm{~nm}$ nos tempos 0 (tubo controle) e após 6 minutos de armazenamento no escuro (os que continham amostra). Com os valores obtidos, foi calculada a porcentagem de inibição do radical ABTS, utilizando a equação expressa na equação 2 .

Equação 2. Equação percentual de inibição do radical ABTS.

$$
P I_{A B T S}=\left[1-\left(\frac{A B S \text { amostra }_{A B T S}}{A B S \text { controle }_{A B T S}}\right)\right] \times 100
$$

Sendo:

$\mathrm{PI}_{\mathrm{ABTS}}=$ Percentual de Inibição do radical ABTS;

ABS amostra ABTS = absorbância da solução de ABTS adicionada da amostra e incubada no escuro por 6 minutos;

$\mathrm{ABS}$ controle ${ }_{\mathrm{ABTS}}=$ absorbância do controle sem adição de amostra no tempo 0 .

\subsubsection{Determinação da atividade antioxidante por DPPH}

A atividade antioxidante do extrato também foi determinada pelo método de captura do radical livre 2,2-difenil-1picrilhidrazila (DPPH) de acordo com a metodologia de Kim et al. (2002) adaptada por Lima et al. (2014). De acordo com os autores, este método é baseado na captura do radical DPPH por antioxidantes, onde acarretará uma diminuição da absorbância em $517 \mathrm{~nm}$, podendo esta ser comparada a obtido por um antioxidante conhecido como o TROLOX.

Para determinar da atividade antioxidante do extrato pelo radical DPPH, em tubos de ensaio foram depositados $100 \mu \mathrm{L}$ da amostra diluída e 2,9 mL da solução de DPPH. Foi preparado o controle em outro tudo com $100 \mu \mathrm{L}$ de água destilada e 2,9 $\mathrm{mL}$ da solução de DPPH. Foram homogeneizados e posteriormente, com o espectrofotômetro zerado com etanol, as leituras de absorbâncias foram executadas em $517 \mathrm{~nm}$ nos tempos 0 (tubo controle) e depois de 30 minutos de repouso no escuro (tubos com amostras). O percentual de inibição do radical DPPH foi obtido conforme a equação 3.

Equação 3. Equação percentual de inibição do radical DPPH.

$$
\mathrm{PI}_{\mathrm{DPPH}}=\left[1-\left(\frac{A B S \text { amostra }_{\mathrm{DPPH}}}{\text { ABS } \text { controle }_{\mathrm{DPPH}}}\right)\right] \times 100
$$

Sendo:

$\mathrm{PI}_{\mathrm{DPPH}}=$ Percentual de Inibição do radical DPPH;

ABS amostra DPPH = absorbância da solução de DPPH adicionada da amostra e incubada no escuro por 30 minutos;

ABS controle ${ }_{\mathrm{DPPH}}=$ absorbância do controle sem adição de amostra no tempo 0 . 


\subsection{Análise Estatística}

Todas as análises foram realizadas em triplicatas e os resultados alcançados nelas foram submetidos à análise de variância (ANOVA) ao nível de 5\% de significância e o teste de Tukey, que avaliou a diferença entre os pares de tratamentos entre si, isso com o auxílio do programa SPSS, versão 17.0.

\section{Resultados e Discussões}

\subsection{Curva de secagem da amêndoa}

Após obter os dados experimentais a partir da secagem, observou-se que a temperatura do ar de secagem utilizado no processo teve influência na curva de secagem, pois quanto maior a temperatura mais rápido se obtém a umidade de equilíbrio constante, que é atingida quando o material perde totalmente o seu teor de água, neste caso, sendo necessário um período de 13 horas para ele alcançar peso constante. Leva-se em consideração que a temperatura de $60^{\circ} \mathrm{C}$ utilizada no trabalho é aplicada para produtos agrícolas devido ser intermediária e não agredir tanto o teor nutricional.

Com isso, a curva de secagem da amêndoa do caroço da manga no decorrer do tempo está representada na Figura 1 abaixo.

Figura 1. Curva de secagem da amêndoa do caroço da manga $\left(60^{\circ} \mathrm{C}\right)$.

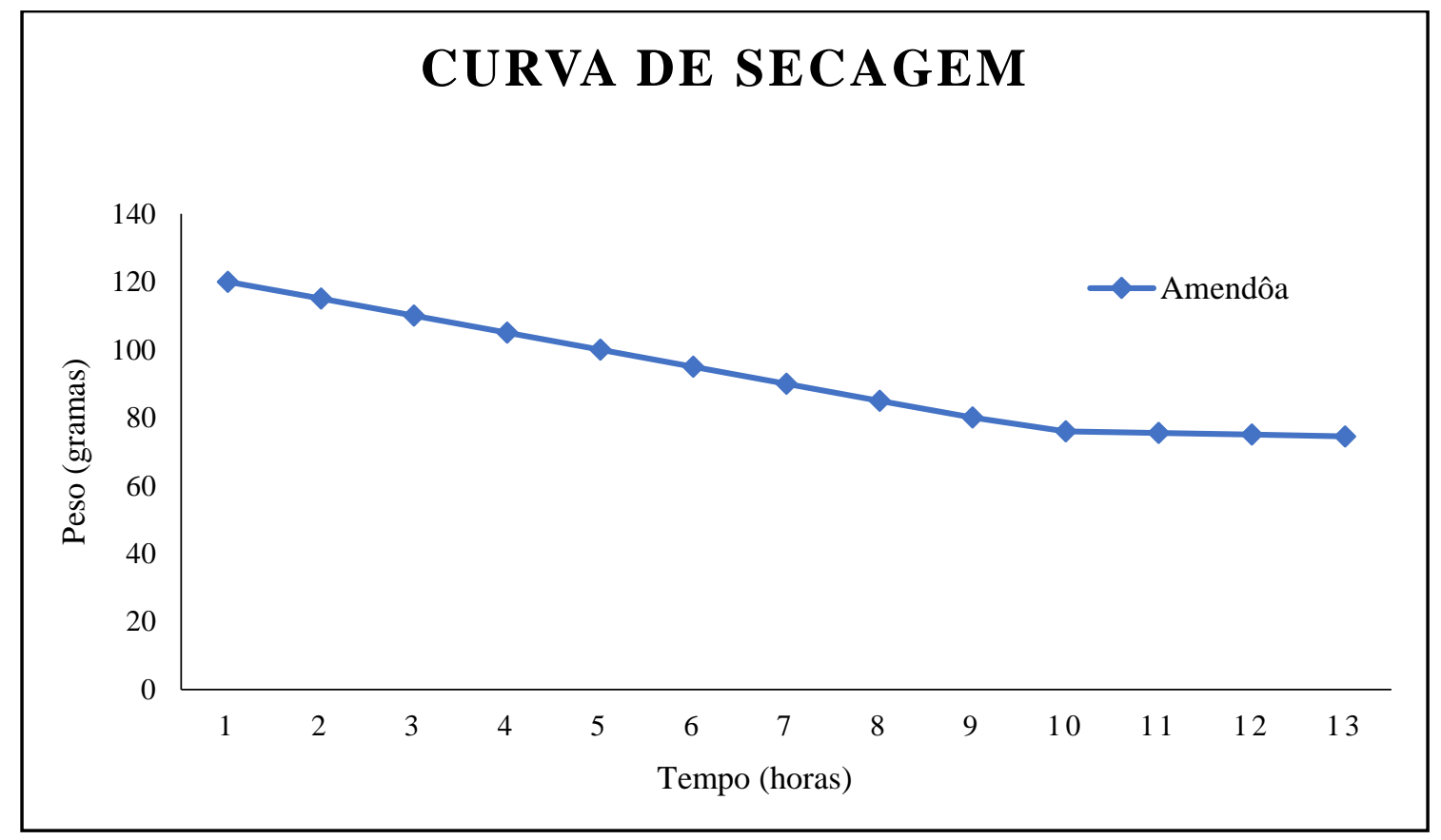

Fonte: Autores (2021).

Durante o período de secagem, as amêndoas demonstraram uma redução gradativa de peso. Devido à diferença de temperatura, quando as amêndoas foram depositadas no secador, ocorreu uma troca de calor do ambiente quente com o material úmido. Portanto, durante a elevação da temperatura gerada pelo equipamento, a pressão do vapor d'água das amêndoas aumentou. A diferença de pressão do vapor entre o ar quente do espaço e a superfície da matéria-prima, fez com que a massa desta fosse transferida para o ar, de modo que o vapor fosse arrastado do produto. Consequentemente, o teor de umidade caiu significativamente, vindo atingir peso constante das amêndoas. 


\subsection{Rendimento dos Extratos}

Com relação aos rendimentos de extratos obtidos, calculado conforme equação 1 , foram alcançados os rendimentos de extração (em percentagens), que estão demonstrados na Tabela 2, onde é possível visualizar o melhor desempenho de extração quanto aos métodos, em conjunto com os solventes.

Tabela 2. Rendimentos dos extratos.

\begin{tabular}{cccc}
\hline Solventes & Soxhlet & Ultrassom & Maceração \\
\hline Etanol & $18,78 \%$ & $11,35 \%$ & $9,12 \%$ \\
Hexano & $9,78 \%$ & $6,93 \%$ & $5,71 \%$ \\
Acetato de Etila & $15,45 \%$ & $6,34 \%$ & $7,26 \%$ \\
\hline
\end{tabular}

Fonte: Autores (2021).

Entre melhor método junto com solvente, a extração por Soxhlet utilizando etanol expressou um maior percentual de rendimento de extrato, obtendo $18,78 \%$. Isso ocorreu devido o etanol ser mais polar que o hexano e o acetato de etila, assim extraindo outros compostos além do extrato da amostra. Também, o fato do sistema de Soxhlet ser executado sob aquecimento com a temperatura de ebulição do solvente utilizado, fez com que a tensão superficial e viscosidade deste solvente fossem diminuídas, o que favoreceu a dissolução dos componentes presentes na amêndoa do caroço da manga, assim gerando uma extração mais eficiente, visto que em relação a percentual de extrato com potencial fenólico e atividade antioxidante foi eficiente nesse quesito por apresentar o dobro de massa de extrato que a maceração com etanol.

Tratando das extrações por maceração e assistida por ultrassom, quando comparadas a de Soxhlet, foram obtidos menores rendimentos, por serem métodos realizados em temperatura ambiente, o que fez com que a tensão superficial e viscosidade dos solventes permanecessem altas, dificultando um maior contato com os compostos solúveis, assim reduzindo o percentual de extrato obtido.

\subsection{Compostos Fenólicos e Atividade Antioxidante}

Os resultados de teor de fenólicos totais (método de Folin-Ciocalteu) obtidos no extrato da amêndoa do caroço da manga, como também sua atividade antioxidante (pelos métodos de radicais livres ABTS e DPPH), estão representados na Figura 2. 
Figura 2. Teor de Fenólicos Totais e Atividade Antioxidante do extrato da amêndoa do caroço da manga.

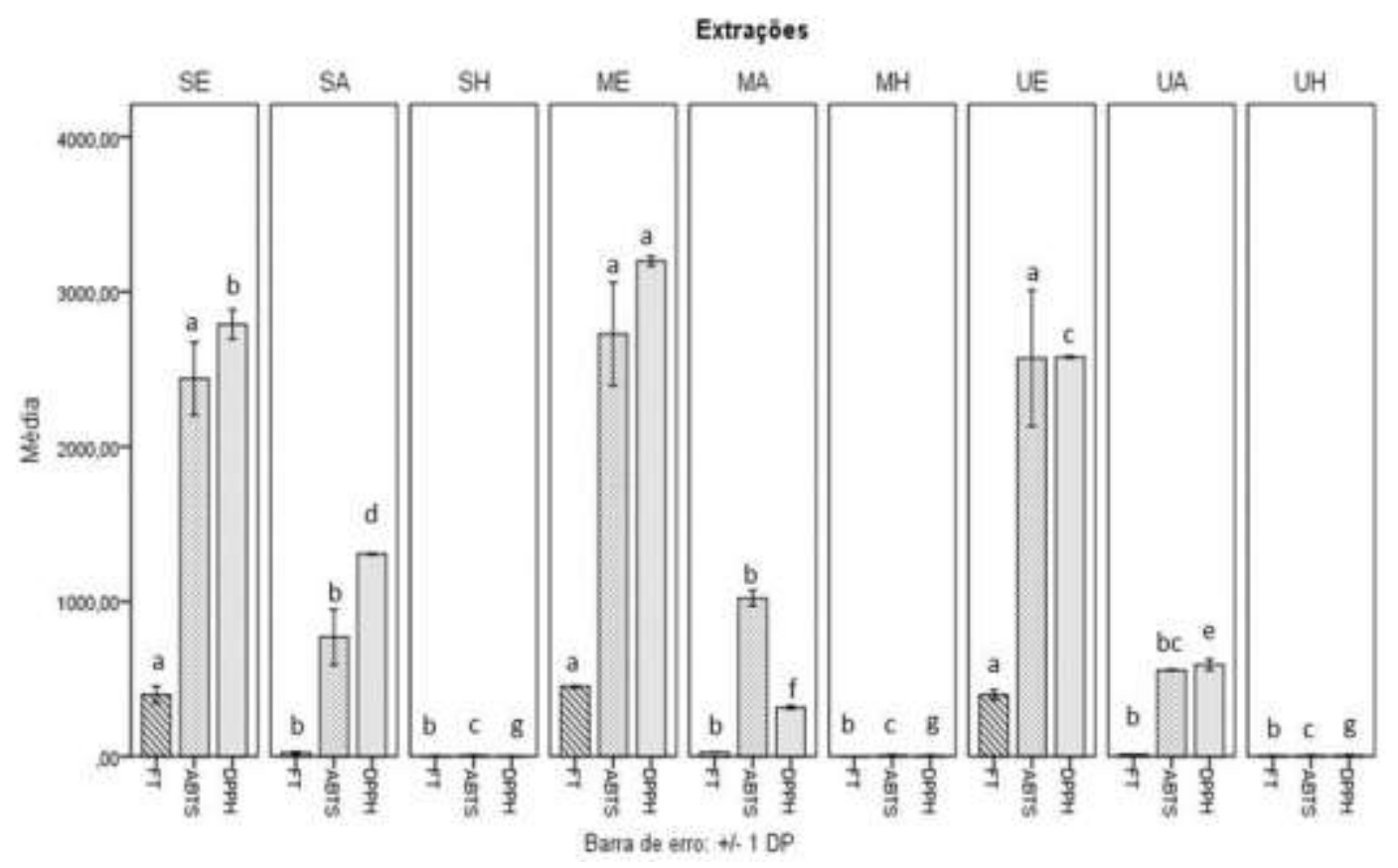

Nota: Legenda: SE=soxhlet com etanol, SA=soxhlet com acetato de etila, SH=soxhlet com hexano; ME=maceração com etanol, $\mathrm{MA}=$ maceração com acetato de etila, $\mathrm{MH}=$ maceração com hexano; UE=ultrassom com etanol, UA=ultrassom coma acetato de etila, $\mathrm{UH}=$ ultrassom com hexano. Barras seguidas de letras iguais não apresentam diferenças entre si pelo teste de Tukey a 5\% de probabilidade de erro.

Fonte: Autores (2021).

Tratando dos compostos fenólicos presentes nos extratos, pôde ser observado que entre os métodos de extrações com diferentes solventes, o extrato que obteve maior relevância nos resultados foi o de maceração utilizando etanol, onde apresentou 451,32 mg EAG/g, valor superior ao encontrado por Láscaris et al. (2020), sendo este de 85,69 mg EAG/g para o extrato de farinha da amêndoa do caroço da manga, obtido através do método de maceração dinâmica com etanol. Constatou-se que para o método Soxhlet utilizando o mesmo solvente, o valor encontrado (398,65 mg EAG/g) foi inferior em relação ao de maceração devido ao aquecimento gerado durante a extração, o que ocasionou a degradação de alguns desses compostos. Além disso, ainda com o etanol, o resultado na extração em banho ultrassônico foi inferior aos mencionados anteriormente (396,95 mg EAG/g), tendo em vista que o tempo de extração neste método foi baixo em relação aos demais, assim diminuindo o contato da amostra com o solvente.

Foi notado que extratos obtidos pelo acetato de etila, que possui polaridade mais baixa que o etanol, apresentou valores intermediários de compostos fenólicos em todos os métodos de extrações, tendo 22,98 mg EAG/g no extrato por Soxhlet; 25,36 mg EAG/g no extrato por maceração e 12,75 mg EAG/g no extrato por ultrassom. Hexano foi o solvente que, para os três métodos de extrações, apresentou menores resultados de teor fenólico (Soxhlet- 4,21 mg EAG/g; Maceração- 2,35 mg EAG/g e Ultrassom4,61 mg EAG/g), por apresentar polaridade nula, assim gerando dificuldades na extração e identificação de compostos bioativos presentes nos extratos.

Souza (2014) estudou os fenólicos na casca da manga, onde no extrato por maceração com etanol obteve 45,2 mg EAG/g. Com isso o teor de fenólicos encontrados no presente estudo foram superiores ao encontrados pelo autor acima, isso deve-se principalmente ao método em que foi analisado, assim considerando que a amêndoa do caroço da manga tem grande potencial fenólico quando comparados ao da casca.

De acordo com o estudo realizado por Arbos et al. (2013) o extrato obtido da farinha da amêndoa do caroço da manga apresentou teor de compostos fenólicos mais levados que no presente estudo, de 3123,13 mg EAG/g. Isso ocorreu devido o 
método qual foi utilizado, sendo este a maceração dinâmica através do shaker, qual realiza extrações sob agitação contínua em um determinado tempo e, se necessário, temperatura.

Com relação à atividade antioxidante por ABTS, foi visto que entre os distintos métodos de extrações utilizando o etanol, os valores obtidos não diferiram entre eles. No entanto, o método que adquiriu maior sequestro de radical livre foi o de maceração, obtendo 2727,23 mM TEAC/g, seguido do método de ultrassom, alcançando 2570,28 mM TEAC/g e Soxhlet, $2436,70 \mathrm{mM} \mathrm{TEAC} / \mathrm{g}$.

No estudo realizado por Láscaris (2020), para atividade antioxidante por ABTS do extrato da farinha da amêndoa da manga, foi encontrado valor inferior, 1370,23 mM TEAC/g, do presente trabalho. Essa variação de resultado justifica-se pelo método de extração (maceração dinâmica) utilizado pelo mesmo, onde a matéria-prima passa um menor período (4 horas) em contato com o solvente, o que ocasiona na menor quantidades de compostos antioxidantes extraídos por este.

Conforme o estudo realizado por Souza (2015), no extrato da casca da manga utilizando o mesmo método (maceração) e solvente (etanol) foi obtido $1287 \mathrm{mM} \mathrm{TEAC/g}$ quanto à atividade antioxidante por ABTS, sendo este valor menor que ao encontrado no atual trabalho. Levando em consideração, a amêndoa do caroço da manga possui maior atividade antioxidante quando comparada a casca da mesma fruta.

Quanto às extrações com acetato de etila, os valores foram inferiores aos do etanol, tendo $1020 \mathrm{mM}$ TEAC/g por maceração; $770 \mathrm{mM}$ TEAC/g pelo método Soxhlet e 556,70 mM TEAC/g por ultrassom. Tratando-se do hexano, ele foi o solvente que em todos os métodos (Soxhlet, maceração e ultrassom) apresentou os menores resultados, sendo 6,0 mM TEAC/g, 6,3 mM TEAC/g e 5,7 mM TEAC/g, respectivamente.

Quanto à atividade antioxidante por DPPH, assim como os resultados obtidos anteriormente, a maceração utilizando etanol permaneceu sendo o método e solvente que apresentaram melhor captura do radical livre em extrato adquirido por esse processo. Nesta técnica, foi alcançado 3198,58 mM TEAC/g, seguido de Soxhlet usando o mesmo solvente, com o valor de 2789,18 mM TEAC/g e ultrassom com 2576,70 mM TEAC/g. O acetato de etila apresentou valores medianos (Soxhlet- 1306,72 mM TEAC/g; Maceração- 315,48 mM TEAC/g e Ultrassom- 593,34 mM TEAC/g), e o hexano, novamente, gerou valores abaixo dos demais em todas as extrações (Soxhlet- 4,0 mM TEAC/g; Maceração- 5,27 mM TEAC/g e Ultrassom- 6,86 mM TEAC/g). Isso se deu por ele ser um solvente de polaridade nula e causar maiores dificuldades para obtenção e identificação dos compostos de ação antioxidante.

Em vista disso, a identificação da atividade antioxidante por capturas dos radicais livres ABTS e DPPH tiveram melhor execução em extratos obtidos através da técnica de maceração com o etanol por ser um método qual não utilizada aquecimento (o que pode degradar alguns compostos), tendo também um período maior contato entre a matéria-prima em questão e o solvente, este apresentando afinidade na extração por possuir alta polaridade, o que consequentemente gera uma maior extração de compostos bioativos, principalmente de natureza antioxidante.

Devido escassez de resultados similares para comparação com os obtidos no presente estudo, no trabalho realizado por Arbos (2013) foi encontrado 88,5\% de atividade antioxidante por DPPH para extrato obtido da farinha da casca da manga e $69 \%$ para farinha obtida da amêndoa do caroço da mesma fruta. Sendo assim, foi impossibilitado de realizar uma comparação mais precisa entre esses, devido à distinção de unidades de medidas entre os valores.

Contudo, foi possível considerar que o método por maceração juntamente com o solvente etanol foi o que apresentou melhor desempenho para todas as análises realizadas, entretanto do ponto de vista econômico o mais viável seria o método de extração por ultrassom com etanol (melhor solvente extrator), já que por maceração em questão requer mais tempo de processo e por Soxhlet há o grande consumo de energia, além da degradação de composto, porém de acordo com os dados obtidos não houve diferença estatística significativa entre os métodos juntamente com os solventes utilizados, podendo aplica-los a depender para onde o extrato será destinado. 


\section{Conclusão}

De acordo com os resultados obtidos neste trabalho, conclui-se que entre os métodos de extrações utilizados, o sistema Soxhlet associado com o solvente etanol, alcançou o melhor desempenho em questão de rendimento. Todavia, amêndoa do caroço da manga (Mangifera indica L.) é potencialmente rica em compostos fenólicos e atividade antioxidante, onde extratos obtidos pela extração por maceração com etanol apresentou maior teor expressivo para estes quesitos.

No decurso dos resultados alcançados, foi possível visualizar, também, que os compostos fenólicos estão mais presentes em extratos com solventes de alta e média polaridade, tendo dificuldades para serem obtidos em solventes de baixa.

Com isso, o resíduo agroindustrial da manga é economicamente interessante para seu aproveitamento, visando à redução do descarte inadequado e o uso na indústria de alimentos em substituição aos antioxidantes sintéticos, como também em elaboração de alimentos funcionais.

Aconselha-se a utilização de outras técnicas de extração, como também outros tipos de solvente uma vez que a manga (Mangifera indica L.) é uma variedade muito presente na região do Submédio do Vale do São Francisco e apresenta boas propriedades para a elaboração de extratos.

\section{Agradecimentos}

Ao Instituto Federal do Sertão Pernambucano (IF Sertão - PE), pela concessão da bolsa de iniciação científica.

\section{Referências}

Abrafrutas. (2020). Dados estatísticos. Dados de exportação do $1^{\circ}$ semestre de 2020. Associação Brasileira dos Produtores Exportadores de Frutas e Derivados (Abrafrutas). https://abrafrutas.org/2020/09/23/dados-de-exportacao-do-1a-semestre-de-2020.

Agrianual. (2016). AGRIANUAL Anuário da Agricultura Brasileira (2016). IEG /FNP Agribusiness intelligence.

Arbos, K. A., StevanI, P. C., \& Castanha, R. de F. (2013). Atividade antimicrobiana, antioxidante e teor de compostos fenólicos em casca e amêndoa de frutos de manga. Rev. Ceres, 60, 161-165.

Brizola, R. \& Bampi, G. B. (2014). Desenvolvimento de barras alimentícias com adição de farinha de banana verde. Unoesc \& Ciência - ACBS, 5, 63-68.

FAO. Food and Agriculture Organization of the United States (2013). Produção brasileira de frutas 2013. Banco de dados. FAO, 2013.

Gu, Z., Chen, D., Han, Y., Chen, Z, Gu, F. (2008). Optimization of carotenoids extraction from Rhodobacter sphaeroides. LWT. 41, $1082-1088$.

IBGE. (2016). Banco de dados agregados: Sistema IBGE de recuperação automática: SIDRA. http://www.ibge.gov.br.

Instituto Adolfo Lutz (São Paulo). Métodos físico-químicos para análise de alimentos /coordenadores. (2008). Odair Zenebon, Neus Sadocco Pascuet e Paulo Tiglea - São Paulo: Instituto Adolfo Lutz, p.1020, versão eletrônica.

Kim et al. (2002). Free radical scavenging activity of red ginseng aqueous extracts. Toxicology, 172, 149-156.

Láscaris, M. P. S. et al. (2020). Extração, caracterização, atividade antioxidante e antimicrobiana de resíduos de manga (Tommy Atkins). Research, Society and Development, 9, e3519108696.

Lima, J. R., Pontes, L. dos S., Goiana, M. L., Tajra, T. F. (2017). Extração de óleo da amêndoa de manga. Embrapa Agroindústria Tropical, Fortaleza, Ceará, UFC.

Lima, M. dos S., Silani, I. de S. V., Toaldo, I. M., Corrêa, L. C., Biasoto, A. C. T., Pereira, G. E., Bordignon-Luiz, M. T., Ninow, J. L. (2014). Phenolic compounds, organic acids and antioxidant activity of grape juices produced from new Brazilian varieties planted in the Northeast Region of Brazil. Food Chemistry, 161, 94-103.

Macagnan, F. T., Moura, F. A., Santos, L. R., Bizzani, M., Silva, L. P. (2014). Caracterização nutricional e resposta sensorial de pães de mel com alto teor de fibra alimentar elaborados com farinhas de subprodutos do processamento de frutas. Boletim do Centro de Pesquisa de Processamento de Alimentos, 32.

Naffati, A., Vladic J., Pavlic, B., Radosavljevic, R., Gavaric, A., Vidovic, S. (2017). Recycling of filter tea industry by-products: Application of subcriticalwater extraction for recovery of bioactive compounds from A. uvaursiherbal dust. Journal of Supercritical Fluids, 121, 1-9.

Nascimento Filho, W. B., Franco, C. R. (2015). Avaliação do potencial dos resíduos produzidos através do processamento agroindustrial no Brasil. Revista Virtual de Química, 7, 1968-1987.

Pedrassolli, I. M., Homem-Junior, A. C., \& Pandolfi, M. A. C. (2015). Aproveitamento dos resíduos de manga das agroindústrias. In: III SIMTEC - Simpósio de Tecnologia da FATEC. Anais. 3 . Taquaritinga. 
Research, Society and Development, v. 10, n. 9, e12010917760, 2021

(CC BY 4.0) | ISSN 2525-3409 | DOI: http://dx.doi.org/10.33448/rsd-v10i9.17760

Pereira, A. S., Shitsuka, D. M., Parreira, F. J., \& Shitsuka, R. (2018). Metodologia da Pesquisa Cientifica. UFSM.

Re et al. (1999). Antioxidant activity applying and improved ABTS radical cation decolorization assay. Free Radical Biology Medicine, $26,1234-1237$.

Sachindra, N. M., Bhaskar, N., \& Mahendrakar, N. S. (2006). Recovery of carotenoids from shrimp waste in organic solvents. Waste Management, 26, 10921098.

SEAB/DERAL - Secretaria da Agricultura e do Abastecimento/ Departamento de Economia Rural do Estado do Paraná. (2020). Fruticultura: Análise da Conjuntura (Prognóstico 2020). <https:// http://www.agricultura.pr.gov.br/sites/default/arquivos_restritos/files/documento/2020-01/fruticultura_2020.pdf. Acesso em 11/01/2021.

Silva, D. C. de M. N. (2004). Determinação experimental de parâmetros de processos na extração supercrítica de óleo essencial de carquela (Baccaris trimera Less). Dissertação (Mestrado em Engenharia de Alimentos), Florianópolis: UFSC.

Silva, P. A. P., Costa Filho, D. V., Silva, A. J., \& Sousa, F. C. (2017). Aproveitamento de Resíduos Agroindustriais na Elaboração de Subprodutos. II Congresso Internacional das Ciências Agrárias.

Singleton, V. L., Rossi, J. A. (1965). Colorimetry of total phenolics with phosphomolybdic-phosphotungstic acid reagents. American Journal of Enology and Viticulture, 16, 144-158.

Souza, M. E. A. O. de et al. (2014). Aproveitamento de casca de manga Tommy Atkins (Mangifera indica Linn) para obtenção de extratos ricos em compostos fenólicos através de diferentes métodos de extração. XX Congresso Brasileiro de Engenharia Química.

Souza, M. E. A. O. de. (2015). Potencial antioxidante de extratos da casca de manga (Mangifera indica L.) da variedade Tommy Atkins obtidos por métodos a baixa e a alta pressão e dimensionamento de uma coluna para extração supercrítica. Florianópolis: UFSC. Tese (Doutorado em En genharia de Alimentos), Departamento de Engenharia Química e Engenharia de Alimentos, Universidade Federal de Santa Catarina. 